\title{
Spendenaufruf Geburtshaus Wilhelm Conrad Röntgen
}

Wohl kaum eine andere Entdeckung der Neuzeit hat derart tiefgreifende Veränderungen in den Naturwissenschaften, in der Medizin und in den Kulturwissenschaften ausgelöst wie die Entdeckung der X-Strahlen durch Wilhelm Conrad Röntgen. Der Blick in das Innere der Materie, den Röntgens Entdeckung eröffnete, führte in den folgenden Jahren und Jahrzehnten zu einer unübersehbaren Fülle von Erkenntnissen und Anwendungen in Wissenschaft und Technik. Röntgens Entdeckung darf mit Fug und Recht eine Sternstunde der Menschheit genannt werden.

Ein ungewöhnlicher Glücksfall eröffnete vor 2 Jahren für die Deutsche Röntgengesellschaft die Gelegenheit, Röntgens Geburtshaus, welches sich in den vergangenen 170 Jahren kaum in seiner äußeren Gestalt verändert hatte, zu erwerben. Es bestand kein Zweifel, dass der schlechte bauliche Zustand des Hauses erhebliche Investitionen in die Sanierung und Renovierung erfordern würde. Dessen ungeachtet stand für alle Beteiligten fest, dass der Aufwand für Erhalt und die Pflege dieses Kleinods in keinem Verhältnis zum unschätzbaren Erbe seines ehemaligen Bewohners steht.

Nachdem nun alle erforderlichen bautechnischen Untersuchungen abgeschlossen sind und das zukünftige Nutzungskonzept dieses kulturhistorischen Kleinods als Museum und Tagungsort mit dem Denkmalschutz abgestimmt ist, kann nun mit der umfassenden Sanierung des Hauses begonnen werden.

Wilhelm Conrad Röntgen hat seine Entdeckung von Anfang an und ohne Wenn und Aber als Geschenk an die Welt verstanden und jedes Angebot einer wie auch immer gearteten „Vermarktung“ entschieden abgelehnt. Mit dem Erwerb seines Geburtshauses durch die Deutsche Röntgengesellschaft bietet sich nun die Möglichkeit, dieses Haus zu einem gemeinsamen Erbe der Naturwissenschaften und der Medizin zu gestalten und somit das Andenken an Wilhelm Conrad Röntgen zu fördern und zu pflegen.

Mit dem Erwerb und den beginnenden Renovierungsarbeiten ist ein 1 . wichtiger
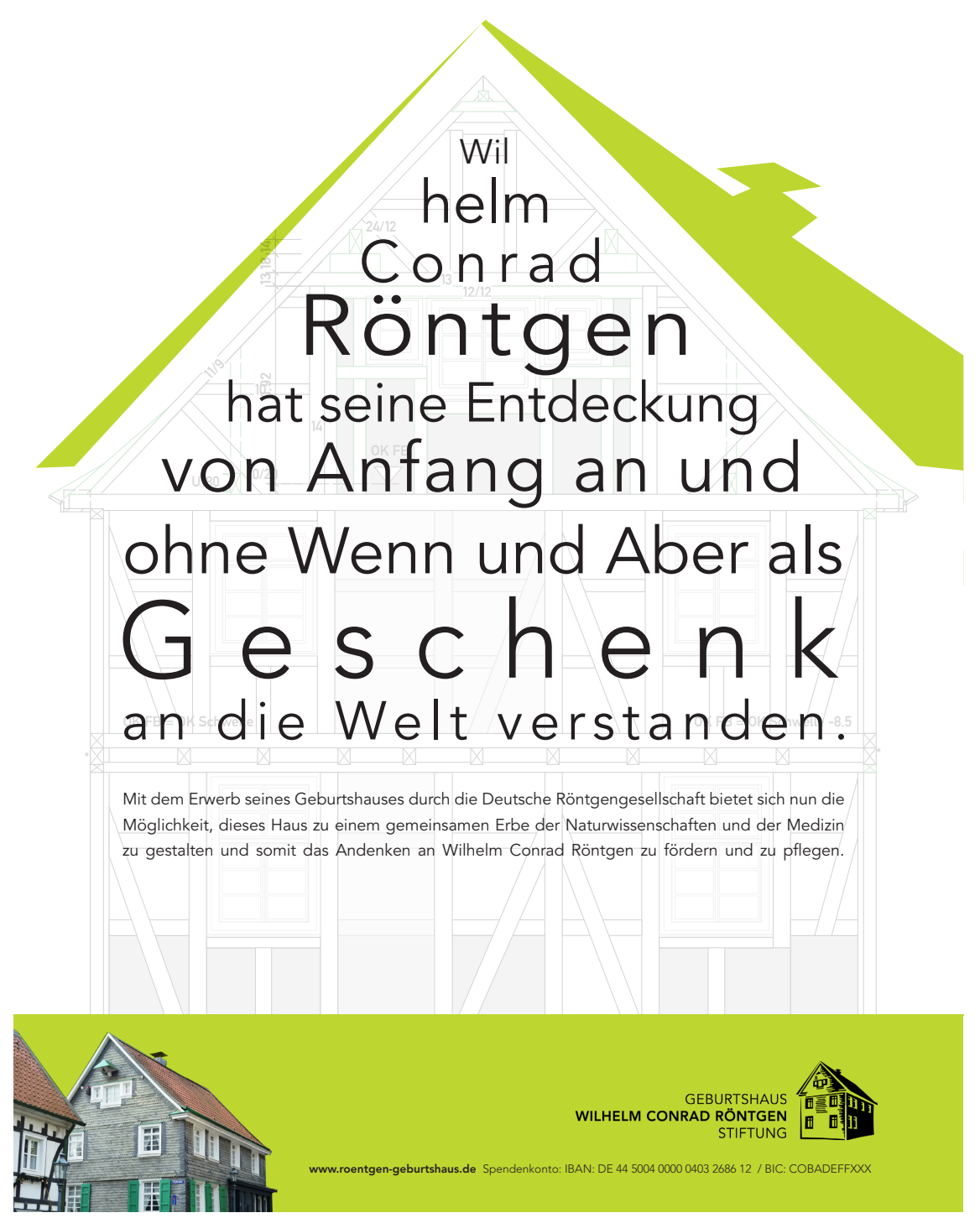

Schritt getan. Um unser Ziel zu erreichen bedarf es jedoch des Engagements aller, die sich dem Erbe von W. C. Röntgen verpflichtet fühlen.

Es ergeht herzliche Einladung, sich als Spender, Förderer oder als Sponsor zu engagieren!

\section{Für die Geburtshaus Wilhelm Conrad Röntgen Stiftung: \\ Prof. Dr. med. em. Ulrich Mödder \\ Dipl. theol. Bernhard Lewerich}

Für die Deutsche Röntgengesellschaft e.V. : Prof. Dr. med. Norbert Hosten
Weitere Infomrationen zum Stand der Baumaßnahmen und zu den Fördermöglichkeiten unter

www.roentgen-geburtshaus.de

\section{Spendenkonto}

Deutsche Röntgengesellschaft e.V. Konto Nr.: 403268612

BLZ: 50040000

Commerzbank Neu-Isenburg IBAN: DE 44500400000403268612 BIC: COBADEFFXXX

(Das Spendenkonto wird entsprechend Stiftungssatzung von der DRG verwaltet.) 